\title{
Lomonosov Moscow State University Develops Interdisciplinary Degree Programs in Materials Science
}

The decision to establish the Higher School of Materials Sciences (HSMS) within Lomonosov Moscow State University (MSU) was issued on January 30, 1991. This decision was made jointly by the USSR Ministry of Education and the Board of the USSR Academy of Sciences. This article describes the interdisciplinary program, but first reviews the reforms in science education that have led up to the new development.

\section{Before Educational Reform in the Sciences in Russia}

For the past 30 years, Soviet educational and research systems were under strong ideological pressure with very little flexibility for dynamic multidisciplinary development. The educational system was divided into specialized institutes of technology (about 300) that included materials engineering and materials technology, and classical universities (about 40) that taught basic science and the humanities (see Figure 1). The discipline of materials science did not yet exist in the system. The technological institutes were extremely specialized, such as the Institute of Metals and Alloys, the Academy of Fine Chemical Technology, the Academy of Textile Materials and Processing, and the Institute of Electronics Materials. A considerable part of the educational programs in these technical universities were classified, and openness, flexibility, and international interdisciplinary cooperation were excluded. At the same time, many of them were closely connected to applied research institutes within the military complex and were supported relatively well from the national budget. Most of their graduate students and courses were oriented to military industrial activity.

Basic science was taught in the other, much smaller part of the Soviet educational system-classical universities. Courses included physics, chemistry, mechanics, biology, mathematics, and a weakly developed applied-science curriculum, but no engineering programs. Graduate students were mainly directed to research institutes of the USSR Academy of Sciences. The Academy was supplied with modern equipment of much better quality than that given to the classical universities, but much less as compared with the military-oriented research institutes. Because this curriculum prevented classical universities from addressing the whole system of science-
Yu.D. Tretyakov

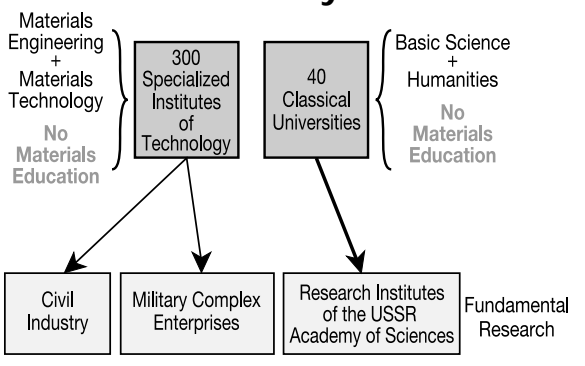

Figure 1 . The education system in Russia before reform.

from basic to applied science, then to engineering - the basic science achievements of classical university academics had relatively weak influence on new technologies and the development of advanced products. This was true even though all of the Russian Nobel Laureates-including L.D. Landau, I.E. Tamm, and N.N. Semyenovwere university professors.

The so-called perestroika, started in the former Soviet Union in 1985, provided opportunities for the rapid development of Russian society, including its research and educational systems. It was not by chance that I. Pimental's Committee Report, published in the United States by the National Academy Press in October 1985, was immediately translated into Russian and became a starting point for the creation of a similar Soviet committee under V.A. Legasov, who had full support of the president of the USSR Academy of Sciences, A.P. Alexandrov. As the result of this activity, the National Soviet Research Program was created, designed to have a strong impact on new advanced materials and technology development. Pimental's report was followed by a book co-authored with I. Coonron in

Education Exchange highlights experiences of scientists and engineers with local schools $(\mathrm{K}-12)$, community programs, and university programs, along with helpful hints and resources. If you would like to share your own involvement in science education, contact $M R S$ Bulletin, Materials Research Society, 506 Keystone Drive, Warrendale, PA 15086-7573 USA; fax 724-7798313; e-mail Bulletin@mrs.org.
1992, titled Opportunities in Chemistry Today and Tomorrow, which, upon its translation in Russian, rapidly sold out its press run of 5,000.

The first attempt to realize the new Materials Science Education Program within Soviet classical universities was made in 1986. The Chernobyl disaster, along with the discovery of a completely new generation of superconductors (HTSC ceramics) by J.Y. Bednordz and K.A. Muller, also contributed to this educational revolution. These two distinct events turned out to have one similarity: They illustrated the effectiveness of combining chemistry and physics as interdependent sciences, thus discovering the benefits of their interdisciplinary nature. The resulting "Advanced Materials and Technologies Program" was realized at the MSU Department of Chemistry due to the effort of V.A. Legasov. Courses in mathematics, physics, solid-state chemistry, materials science, and materials engineering were included in the curriculum for chemistry students. While more than 100 students graduated from this program, the strict departmental structure inhibited the realization of a completely interdisciplinary approach. S. Florman in ASEE Prism 1997 wrote that a combination of both disciplinary hubris and academic territoriality militated against cooperative ventures across disciplinary and administrative boundaries.

Figure 2 illustrates the reformed educational system currently in use. The 300 technical universities - transformed from institutes during 1993-1995-teach materials engineering, materials technology, and humanities, and continue their affiliation with the military complex, but also with private enterprises. However, over $80 \%$ of technical university graduates go into the marketing, management, advertising, and promotion fields, leaving only $20 \%$ of graduates as scientists or professionals. This constitutes a "brain drain" within the country. The now 100 classical universities continue to teach basic science and humanities, but have also incorporated materials science as an interdisciplinary field. These universities continue their affiliations with the research institutes of the USSR Academy of Sciences.

\section{HSMS Program}

The flexibility of the political system existing in the USSR in the middle of the 


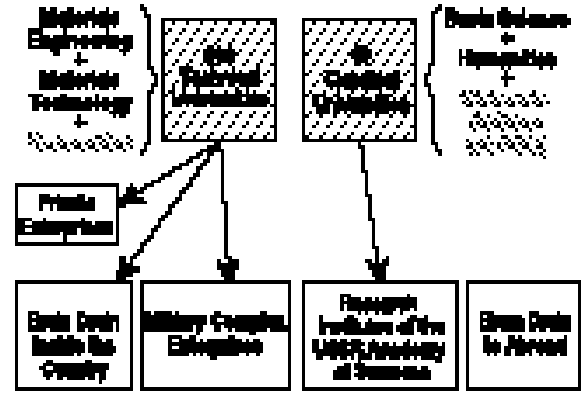

Figure 2. The reformed educational system currently in use in Russia.

perestroika (1988-1990) created favorable conditions for more openness and flexibility in the educational system. It presented great opportunities for innovation in the educational institutions, with no disciplinary subdivisions. At MSU, the researchers' suggestions to create a new, interdisciplinary educational faculty dealing with materials science received strong support from the Education Ministry as well as the Academy of Sciences. This venture was pursued at the Lomonosov MSU for several reasons. The University housed an extremely high scientific potential of academics in, for example, mathematics, physics, chemistry, mechanics, and computer sciences. Because there were no conventional engineering departments dealing with metallurgy, ceramics, or polymer technologies, no serious opposition arose from university staff. At the same time, MSU professors were interested in advanced materials problems as their basic science activity.

HSMS, as an interdisciplinary and independent department of MSU, was created to serve as a model of interdisciplinarity. Features of the department included the integration of relatively young talented academics belonging to the traditional departments who were interested in creating a completely new materials science education curricula; the elimination of a gap between MSU professors and Academy of Sciences Institutes researchers; and internationalization of educational and research activity on a much larger scale than existed before- - even at MSU, which used to be relatively open for international cooperation, even during the Soviet era. The goal of HSMS was to educate a new generation of materials researchers who would be not just specialists, but generalists with practical experience as well as an excellent basic-science background.

According to the MSU Scientific Council's decision, in order to select the most capable young people, the number of first-year HSMS students was limited to 25 . An original entrance-exam system was created that consisted of two steps. The preliminary step offered secondary-school graduates an examination in mathematics, chemistry, and physics by correspondence. About 60 people were admitted to the second round of qualification, written exams carried out at the University and under its control. This selection activity occurred cross-country, raising the number of accepted students from year to year. The applicants $(A)$ per one position $(P)$ increased from 4.5 in 1996, to 7.0 in 1997, 9.5 in 1998, and 12.9 in 1999. In 1999, HSMS showed the highest-ever $A / P$ among MSU departments: $A / P=3.1,3.0$, and 7.4 for physics, chemistry, and mathematics departments, respectively (see Figure 3). Moreover, HSMS had the highest ratio of non-Moscovites/Moscovites among MSU departments (96\% in 1998).

The strong competition among HSMS applicants resulted in a high-level group of first-year students. Because of this, the educational program was faced with much more serious demands than planned. Training itself lasts for 5.5 years. After the first four years of study, HSMS students were able to obtain a BS degree, while an additional 1.5 years led to an MS degree and the Diploma, verifying graduation from the Lomonosov Moscow State University. Every year consists of two semesters; every semester lasts for 21 weeks, including 18 weeks of ordinary training, one week of examination, and two weeks of research. Students' activity during every semester is evaluated by a special rating system. The rating results are

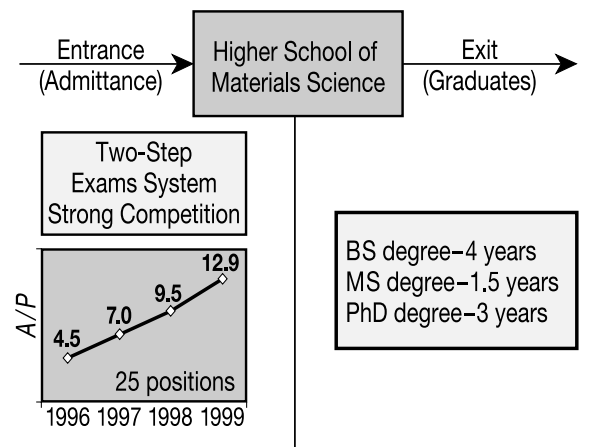

11 semesters +3 years $\mathrm{PhD}$ study Every semester $=21$ weeks including: 18 weeks of ordinary training 1 week for exam

2 weeks of research

Figure 3. The Higher School of Materials Science Program at Lomonosov Moscow State University. A/P means applicant per position. taken into account during the examination session. The curriculum includes compulsory, partly selective, and fully selective courses. See Table I for a list of such courses.

In 1998, the PhD program was implemented in chemistry, physics, and mechanics of materials for HSMS graduates. This program is available for any BS and MS degree recipients who are able to pass entrance examinations in a specialty and in English.

Since its creation, the HSMS department has enabled several opportunities while still resolving a few obstacles. The small size of the department lets it serve as a dynamic and relatively inexpensive model of an interdisciplinary school that is applicable to many Russian (and non-Russian) nontechnical universities. The admission procedure described earlier enables an advanced-degree program in materials science, while its overall rating system continuously pushes students to excel in their work. The students' research activity develops under individual ("face-to-face") supervision, beginning with their first year of studies. The department integrates capable researchers from the mathematics, mechanics, physics, and chemistry departments as well as from some research institutes of the Russian Academy of Sciences under an HSMS umbrella to train and supervise students. Most HSMS undergraduate, graduate, and $\mathrm{PhD}$ students are financially supported through their participation in different research projects. Furthermore, their research activity gives students a chance to receive the Soros scholarship* much more often (15 times) than the average level among MSU students. About $30-35 \%$ of undergraduate training consists of laboratory experiments under tutors' supervision, with 5-6 students per tutor. Humanities courses, including English, French, history, economics, philosophy, heuristics, and management, compose a remarkable part of the program. HSMS students who do not participate at Russian or international scientific meetings are encouraged to give oral or poster contributions at least twice a year at a student conference. Due to international cooperation agreements with Fourier University in Grenoble (France), Munster University (Germany), Wisconsin

*The Soros scholarship was founded by the Soros Foundations (after George Soros) in 1994. The Soros Foundations are a network of foundations, programs, and institutes established by the well-known millionaire and philanthropist to support science and scientists in the world, especially in the former communist countries of Central and Eastern Europe. For more information, visit www.soros.org and www.osi.ru. 
Table I. Higher School of Materials Sciences (HSMS) Curriculum

\section{First year (compulsory courses)}

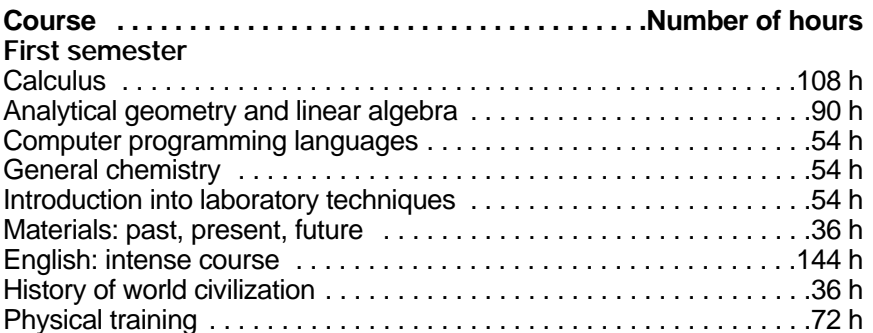

Course .........

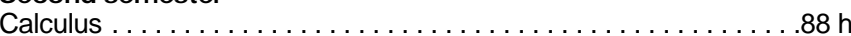

Differential equations ......................56 h

Fundamental computer algorithms and numerical computations . . .48 h Dynamic and statistical mechanics and thermodynamics . . . . . . .126 h Chemistry of elements and qualitative analysis (including labs) . . .198 h English-supporting course ...................128 Physical training .........................64h

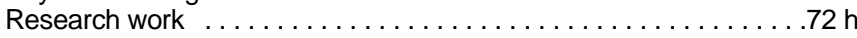

\section{Third semester}

\section{Second year (compulsory courses)}

Calculus . . . . . . . . . . . . . . . . . . . . . . $74 \mathrm{~h}$

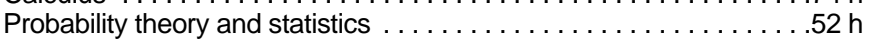

Programming and computers ....................

Physics of electric and magnetic phenomena . . . . . . . . . . $126 \mathrm{~h}$

Organic chemistry including labs . . . . . . . . . . . . . . . . . 234 h

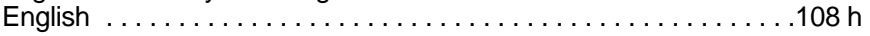

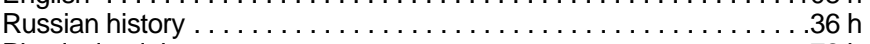

Physical training .........................72 h

Research work ........................

Fourth semester

Theory of functions of complex variables . . . . . . . . . . . . . 54 h

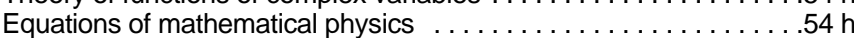

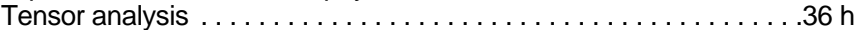

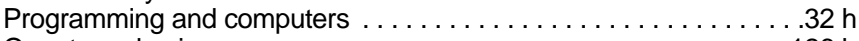

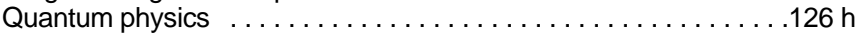

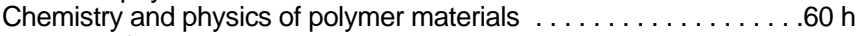

Analysis of substances and materials $\ldots \ldots \ldots \ldots \ldots \ldots \ldots \ldots \ldots \ldots \ldots h$

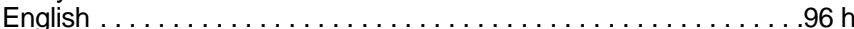

History of Russian culture . . . . . . . . . . . . . . . $32 \mathrm{~h}$

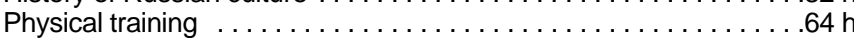

Research work ...........................

\section{Third year (compulsory courses)}

\section{Fifth semester}

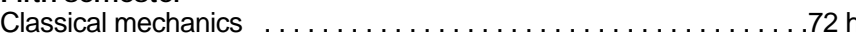

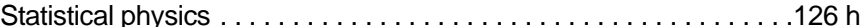

Chemical thermodynamics of materials $\ldots \ldots \ldots \ldots \ldots \ldots \ldots .54 \mathrm{~h}$

Phase equilibrium in materials-forming systems ...................

Thermodynamics of solid-state reactions $\ldots \ldots \ldots \ldots \ldots \ldots \ldots 24 \mathrm{~h}$

Introduction in chemical kinetics $\ldots \ldots \ldots \ldots \ldots \ldots \ldots \ldots \ldots \ldots \ldots \ldots \ldots \ldots \ldots .24 \mathrm{~h}$

English ................................... . . .

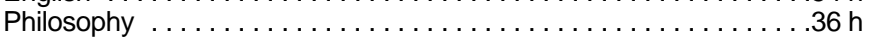

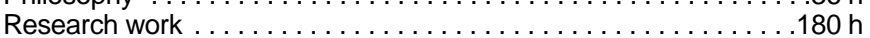

\section{Fourth year (limited selective courses)}

\section{Seventh semester}

Theory of determining correlation $\ldots \ldots \ldots \ldots \ldots \ldots \ldots \ldots . \ldots \ldots h$

Physics of superconductors ......................

Physics of magnetic and dielectric materials $\ldots \ldots \ldots \ldots \ldots \ldots .54 \mathrm{~h}$

Physics of narrow-gap semiconductors $\ldots \ldots \ldots \ldots \ldots \ldots \ldots .27 \mathrm{~h}$

Chemical physics of solids ......................... $40 \mathrm{~h}$

Chemical physics of dispersed solids $\ldots \ldots \ldots \ldots \ldots \ldots \ldots \ldots 40 \ldots \ldots$

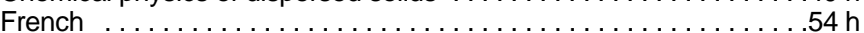

Modern economic theories $\ldots \ldots \ldots \ldots \ldots \ldots \ldots \ldots \ldots \ldots . . \ldots 2 \mathrm{~h}$

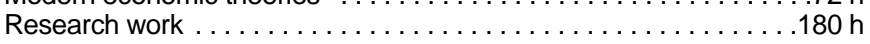

\section{Fifth year (limited selective courses)}

\section{Ninth semester}

Introduction in deterministic chaos theory $\ldots \ldots \ldots \ldots \ldots \ldots .36 \mathrm{~h}$ Nonlinear dynamics approach in materials engineering . . . . . . . $36 \mathrm{~h}$

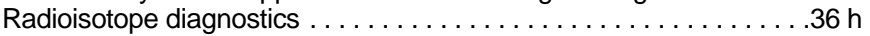

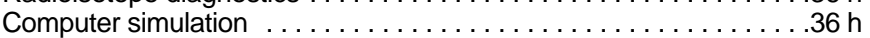

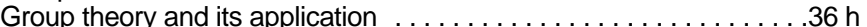

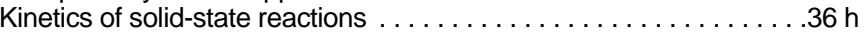

New generations of functional materials $\ldots \ldots \ldots \ldots \ldots \ldots \ldots 36 \mathrm{~h}$

Advanced inorganic chemistry . .................... $36 \mathrm{~h}$

Chemistry and technology of superconductor materials ........36 h

Crystals growth and thin-film technology . . . . . . . . . . . . $36 \mathrm{~h}$

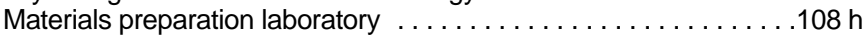

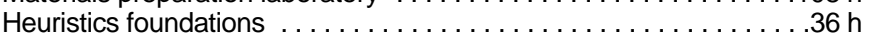

Research work ...............................396 h
Sixth semester

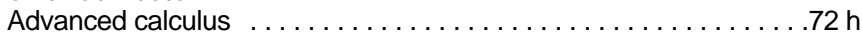

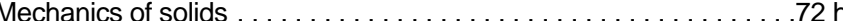

Introduction in solid-state physics . . . . . . . . . . . . . $63 \mathrm{~h}$

Physics of semiconductors ........................ $72 \mathrm{~h}$

Structural chemistry and chemistry of crystals $\ldots \ldots \ldots \ldots \ldots \ldots .6 \mathrm{~h}$

$\mathrm{X}$-ray diffraction in materials science $\ldots \ldots \ldots \ldots \ldots \ldots \ldots .64 \mathrm{~h}$

Solid state spectroscopy . . . . . . . . . . . . . . . . . . . $32 \mathrm{~h}$

English ..........................

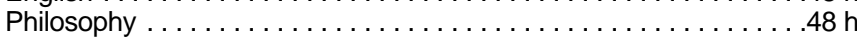

Research work .............................. 180 h

Eighth semester

Structural mechanics and mechanics of destruction $\ldots \ldots \ldots \ldots 68 \mathrm{~h}$

Physics of disordered mediums $\ldots \ldots \ldots \ldots \ldots \ldots \ldots .27 \mathrm{~h}$

Two-dimensioned structures and superstructures $\ldots \ldots \ldots \ldots \ldots .27 \mathrm{~h}$

Experimental methods of condensed matter $\ldots \ldots \ldots \ldots \ldots \ldots \ldots .48 \mathrm{~h}$

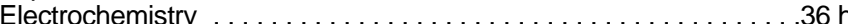

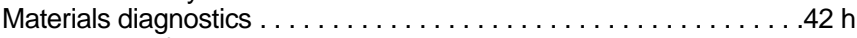

Technology of inorganic materials $\ldots \ldots \ldots \ldots \ldots \ldots \ldots \ldots 42 \mathrm{~h}$

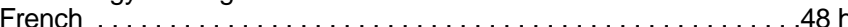

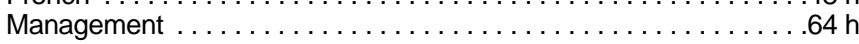

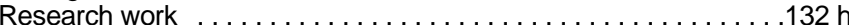

Tenth semester (fully selective courses)

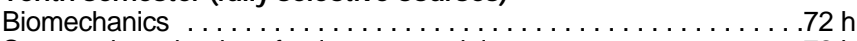

Structural mechanics of polymer materials $\ldots \ldots \ldots \ldots \ldots \ldots .72 \mathrm{~h}$

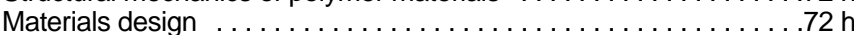

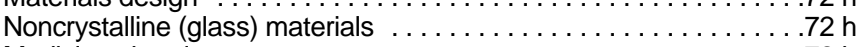

Medicine chemistry ............................. $72 \mathrm{~h}$

Training in research institutes of the Russian Academy of Sciences $.360 \mathrm{~h}$

New laboratory experiment development ..............216 h

Research work .........................106 h

\section{Eleventh semester}

\section{Sixth year (fully selective activity)}

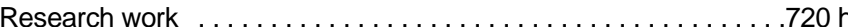

Tutor activity with freshmen students $\ldots \ldots \ldots \ldots \ldots \ldots \ldots \ldots .80 \mathrm{~h}$

MS thesis preparation and presentation to the state commission . . .200 h 
University (U.S.), and joint research projects with non-Russian scientists, some HSMS students have the opportunity to study abroad for 3-6 months. A limited number of $\mathrm{PhD}$ candidates have three years of training, split equally between Fourier University and MSU. Student competitions were made available with the establishment of an awards system that includes international (e.g., EuropeanMaterials Research Society and Academia Europia), national, university, certain Russian Academic of Sciences research institutes, and HSMS prizes (e.g., personal prizes in honor of prominent Russian scientists like the Ipatyev prize). Students are encouraged to publish their research results. In 1999, graduate students published 68 papers, half of them in international journals. HSMS also offers lectures and invited talks by professors worldwide, including F.A. Cotton (Texas A\&M University), R. Hoffman (Cornell University), C.N. Rao (Jawaharal Nehru Center for Advanced Scientific Research, India), P. Hagenmuller (University Bordeaux I), A. West (University of Aberdeen), and

\section{Suggested Readings}

1. R. Roy, ed., "Materials Science and Engineering in the U.S.," Proc. of the National Colloquy on Materials (PSU Press, University Park, PA, 1970). 2. R. Roy, "Pedagogical Theories and Strategies in Education for Materials Research: A Hierarchical Approach," Mat. Res. Soc. Symp. Proc., Vol. 66, (1986) p. 23.

3. J. of Mendeleev All-Union Chemical Society 35 (3) (1990) p. 273. This is a special issue dealing with chemistry and materials education problems (in Russian).

4. R.J. Brook, ed., "Ceramics and Society." Discussion of the Academy of Ceramics Forum'92 (Techna, Faenza, Italy, 1995).

5. I. Melikhov and Yu. Tretyakov, Independent Newspaper, 12 November 1996 and 7 January 1999 (in Russian).

6. I. Dezhina and L. Graham, "Science and Higher Education in Russia," Science 286 (1999) p. 1303
A. Markworth (Ohio State University).

From the very beginning of HSMS's activity (1991), the department was promised large governmental and industrial financial support. The destruction of the USSR and the consequent industrial decline resulted in a very small HSMS budget, equal to $\$ 70,000$ and $\$ 60,000$ in 1996 and 1998, respectively. The department's attempts to receive support from abroad (e.g., from NSF) were unsuccessful. The only exception was the Soros grant $(\$ 14,000)$ that saved HSMS in 1994, when it was on the verge of collapse.

The extremely low budget results in low salaries for professors; lack of student support; and lack of computers, reagents, and such. This has resulted in a significant "brain drain" of professors and students as many have chosen to further their studies and research in other countries, mainly the United States (see Figure 2). In a strive for retention, the department involves researchers of the Russian Academy of Sciences in student admittance and training.

Furthermore, plans were halted on completing construction of a building given by the university administration to the department. The building construction costs $\sim \$ 120,000$, double HSMS's annual budget. HSMS students have been using classrooms from other departments, creating many difficulties.

Despite these problems, HSMS has been able to educate a new generation of researchers for whom materials science is a profession based on a solid background of mathematics, physics, chemistry, and mechanics, with a mission of creating original materials and technologies. In terms of a federal integration program, the department has been able to organize interdisciplinary research activities dealing with new materials engineering based on nonlinear dynamics, self-organization, and deterministic-chaos approaches. The department has been able to contribute to the selection and interdisciplinary training of the most capable young people who are needed for the Russian renaissance.

Since its creation, HSMS has accepted more than 200 students, but because of the very high demands of the program, not all of the students were or will be able to attain the MS or even the BS degree. HSMS students who were able to reach the MS stage received a commendation from the State Commission, and an overwhelming majority continue their education as PhD students-at MSU, in Russian Academy of Science research institutes, and in non-Russian universities, mainly in the United States. In 1997, 14 students received the MS degree; 20 students received it in 1998 and 20 in 1999.

The HSMS department is expected to expand its interdisciplinary links to include life, ecology, and earth sciences (e.g., biomaterials, wastes and raw materials, and earth materials); increase its international cooperation and exchange programs with the materials-education institutions at European, American, and Asian universities; convert HSMS into a self-generating system, enabling it to educate not only materials researchers but also materials-science educators; develop an individual training model with a much more flexible education and research program than is currently practiced; and develop a nonlinear education model, starting from basic sciences and societal concern simultaneously.

Yu.D. Tretyakov, a professor at Lomonosov Moscow State University in Russia, is dean of the Higher School of Materials Science, chair of the Inorganic Chemistry Division, and has supervised the Advanced Materials and Technologies Program in the Department of Chemistry since 1988. He became a Corresponding Member and a Full Member of the Russian Academy of Science in 1984 and 1987, respectively, and has received the Kurnakov prize in chemistry from the Russian Academy of Science and the Lomonosov prize (twice) from Lomonosov Moscow State University. Tretyakov's research activities and interests have been in the areas of chemistry and thermodynamics of solid-state reactions, nonstoichiometry of oxides and chalcogenides, chemistry and technology of materials with nonconventional magnetic and electric properties, cryochemical technology of advanced materials, and high-temperature superconductors. He graduated from Rostov-on-Done University in 1954 and received his PhD degree in 1958 and DrSci degree in 1965.

\section{For information on M RS student opportunities, access} www.mrs.org/membership 